NASA/TM-2000-210246

\title{
NASA GRC Technology Development Project for a Stirling Radioisotope Power System
}

Lanny G. Thieme and Jeffrey G. Schreiber

Glenn Research Center, Cleveland, Ohio 
Since its founding, NASA has been dedicated to the advancement of aeronautics and space science. The NASA Scientific and Technical Information (STI) Program Office plays a key part in helping NASA maintain this important role.

The NASA STI Program Office is operated by Langley Research Center, the Lead Center for NASA's scientific and technical information. The NASA STI Program Office provides access to the NASA STI Database, the largest collection of aeronautical and space science STI in the world. The Program Office is also NASA's institutional mechanism for disseminating the results of its research and development activities. These results are published by NASA in the NASA STI Report Series, which includes the following report types:

- TECHNICAL PUBLICATION. Reports of completed research or a major significant phase of research that present the results of NASA programs and include extensive data or theoretical analysis. Includes compilations of significant scientific and technical data and information deemed to be of continuing reference value. NASA's counterpart of peerreviewed formal professional papers but has less stringent limitations on manuscript length and extent of graphic presentations.

- TECHNICAL MEMORANDUM. Scientific and technical findings that are preliminary or of specialized interest, e.g., quick release reports, working papers, and bibliographies that contain minimal annotation. Does not contain extensive analysis.

- CONTRACTOR REPORT. Scientific and technical findings by NASA-sponsored contractors and grantees.
- CONFERENCE PUBLICATION. Collected papers from scientific and technical conferences, symposia, seminars, or other meetings sponsored or cosponsored by NASA.

- SPECIAL PUBLICATION. Scientific, technical, or historical information from NASA programs, projects, and missions, often concerned with subjects having substantial public interest.

- TECHNICAL TRANSLATION. Englishlanguage translations of foreign scientific and technical material pertinent to NASA's mission.

Specialized services that complement the STI Program Office's diverse offerings include creating custom thesauri, building customized data bases, organizing and publishing research results ... even providing videos.

For more information about the NASA STI Program Office, see the following:

- Access the NASA STI Program Home Page at http://www.sti.nasa.gov

- E-mail your question via the Internet to help@sti.nasa.gov

- Fax your question to the NASA Access Help Desk at (301) 621-0134

- Telephone the NASA Access Help Desk at (301) 621-0390

- Write to: NASA Access Help Desk NASA Center for AeroSpace Information 7121 Standard Drive Hanover, MD 21076 


\section{NASA GRC Technology Development Project for a Stirling Radioisotope Power System}

Lanny G. Thieme and Jeffrey G. Schreiber

Glenn Research Center, Cleveland, Ohio

Prepared for the

35th Intersociety Energy Conversion Engineering Conference sponsored by the American Institute of Aeronautics and Astronautics

Las Vegas, Nevada, July 24-28, 2000

National Aeronautics and

Space Administration

Glenn Research Center 
Available from

NASA Center for Aerospace Information 7121 Standard Drive

Hanover, MD 21076

Price Code: A03
National Technical Information Service 5285 Port Royal Road Springfield, VA 22100 Price Code: A03 


\title{
NASA GRC TECHNOLOGY DEVELOPMENT PROJECT FOR A STIRLING RADIOISOTOPE POWER SYSTEM
}

\author{
Lanny G. Thieme and Jeffrey G. Schreiber \\ National Aeronautics and Space Administration \\ Glenn Research Center \\ Cleveland, Ohio
}

\begin{abstract}
$\underline{\text { Abstract }}$
NASA Glenn Research Center (GRC), the Department of Energy (DOE), and Stirling Technology Company (STC) are developing a Stirling convertor for an advanced radioisotope power system to provide spacecraft on-board electric power for NASA deep space missions. NASA GRC is conducting an in-house project to provide convertor, component, and materials testing and evaluation in support of the overall power system development. A first characterization of the DOE/STC 55-We Stirling Technology Demonstration Convertor (TDC) under the expected launch random vibration environment was recently completed in the NASA GRC Structural Dynamics Laboratory. Two TDCs also completed an initial EMI characterization at NASA GRC while being tested in a synchronized, opposed configuration. Materials testing is underway to support a life assessment of the heater head, and magnet characterization and aging tests have been initiated. Test facilities are now being established for an independent convertor performance verification and technology development. A preliminary FMEA, initial FEA for the linear alternator, ionizing radiation survivability assessment, and radiator parametric study have also been completed. This paper will discuss the status, plans, and results to date for these efforts.
\end{abstract}

\section{Introduction}

NASA Glenn Research Center (GRC) (formerly NASA Lewis Research Center), the Department of Energy (DOE), and the Stirling Technology Company (STC) of Kennewick, WA are developing a Stirling convertor for an advanced radioisotope power system to provide spacecraft on-board electric power for NASA deep space missions. Stirling is being evaluated as an alternative to replace Radioisotope Thermoelectric Generators (RTGs) with a high-efficiency power source and has recently been identified for potential use on the Europa Orbiter and Solar Probe missions now scheduled for launch in the 2006-2007 timeframe. The efficiency of the Stirling system, about $20-25 \%$ for this application, will reduce the necessary isotope inventory by a factor of 3 or more compared to RTGs.
STC has designed, fabricated, and completed first testing of the 55-We Technology Demonstration Convertor (TDC) under contract to DOE ${ }^{1.2}$. The TDC has been baselined by DOE for use in the upcoming missions. Two TDCs are now being tested by STC in a dynamically-balanced opposed arrangement, as shown in figure 1. Both design convertor power and efficiency have been demonstrated. Long life has also been demonstrated on a similar STC 10 -We radioisotope terrestrial convertor, RG-10, that has been on life test at STC for over 54,000 hours $(6.1$ years $)$ with no convertor maintenance and no degradation in performance. NASA GRC is providing technical consulting for this effort under an Interagency Agreement with DOE.

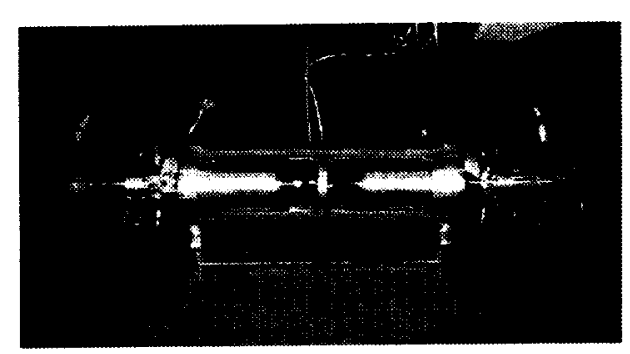

Figure 1. Two opposed 55-We TDC convertors on test (courtesy of STC).

As part of the overall Stirling radioisotope convertor development, NASA GRC is addressing key technology issues through the use of two NASA Phase II Small Business Innovation Research (SBIR) contracts with STC ${ }^{3.4}$. Under the first SBIR, STC demonstrated a synchronous connection of two thermodynamically independent Stirling convertors and a 40 to 50 fold reduction in vibrations compared to an unbalanced convertor. This connection method is now being used to connect the DOE/STC TDC convertors. The second SBIR contract is for the development of an Adaptive Vibration Reduction System that further reduces vibrations under normal operating conditions and will also add the ability to adapt to any changing convertor conditions over the course of a mission. 
NASA GRC is also conducting an in-house project to provide convertor, component, and materials testing and evaluation in support of the overall Stirling radioisotope power system development. The project tasks build on NASA GRC expertise developed as part of previous Stirling research completed by NASA GRC over the last 25 years. Tasks include convertor performance verification, controls technology development, heater head structural life assessment, materials and joining evaluations, linear alternator finite element analyses (FEA), permanent magnet characterization and thermal aging tests, demonstration of convertor operation under launch and orbit transfer random vibration environments, electro-magnetic interference (EMI) characterization of the convertor, ionizing radiation survivability assessment, radiator parametric study, and failure modes and effects analysis (FMEA). This paper will discuss the status and results to date for this in-house project.

NASA GRC has been investigating Stirling radioisotope power systems for deep space missions since about $1990^{5}$. This work grew out of earlier Stirling efforts conducted for DOE for a Stirling automotive engine and for the NASA Civil Space Technology Initiative (CSTI) to develop Stirling for a nuclear power system to provide electrical power for a lunar or Mars base (part of the SP-100 program). NASA GRC also provided technical management for DOE for the Advanced Stirling Conversion System (ASCS) terrestrial dish Stirling project. Overall, NASA GRC has been developing Stirling technologies since the mid-1970's.

Systems using Stirling convertors are being analyzed by NASA GRC for other space applications in addition to Stirling radioisotope power for deep space missions. These include solar dynamic power systems for spacebased radar $^{6}$ and as a deep space alternative to the radioisotope system ${ }^{7.8}$, lunar/Mars bases and rovers, and a combined electrical power and cooling system for a Venus lander.

\section{Convertor Characterization in Launch Environment}

Following initial development of the TDC, the performance goals of electric power output and conversion efficiency had been demonstrated. Mass was projected for a flight version of the TDC that was acceptable for the integrated spacecraft power system. It was also shown that the TDC was based on technologies that were capable of leading to long life and reliability. Although these capabilities might be demonstrated analytically and in laboratory tests, it was unclear what the effect would be on the convertor when subject to the anticipated launch vibration.
Specifications used during the initial design and development of the TDC had no requirement for surviving the random vibration of the launch environment.

Personnel representing DOE, GRC, the Jet Propulsion Laboratory (JPL), and STC worked jointly to develop a test plan to evaluate the effect that vibration would have on the operation and performance of the TDC. The vibration levels for the test are shown in figure 2. The standard workmanship test (NASA-STD-7001) was modified to move the knee of the vibration curve below the $80 \mathrm{~Hz}$ operating frequency of the TDC. Since little was known about the ability of the TDC to withstand vibration, it was decided that the test would proceed incrementally from low vibration levels to higher levels. It was also decided that the TDC would be tested with random vibrations imposed in the axial and lateral directions, and that it would be first tested at workmanship level in each direction before advancing to the flight and qualification level tests. Duration of each vibration test was one minute, with the exception of the qualification tests which lasted three minutes.

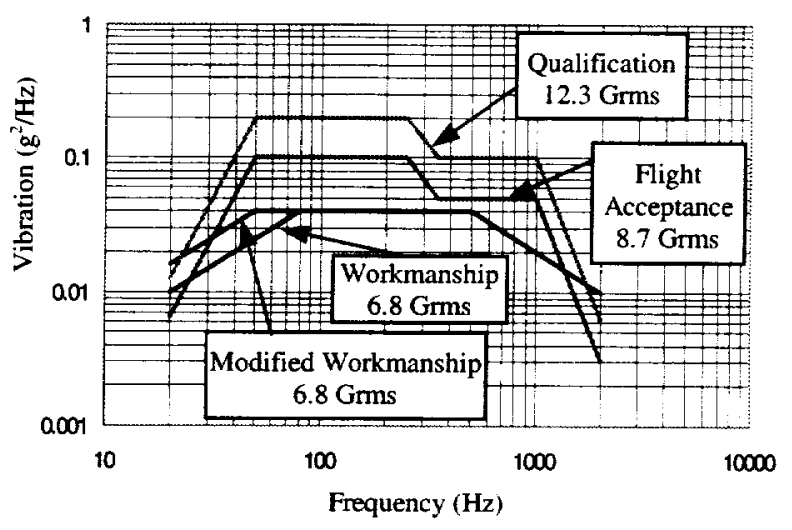

Figure 2. Random vibration test levels.

The TDC mounted in the vibration test fixture is shown in figures 3 and 4 . The TDC was operated at full power and full stroke during each test. Power output was recorded as each test proceeded. Sine sweeps were performed before and after each major test to try to detect any changes in structural integrity that might occur. References ${ }^{9,10}$ discuss the results of these tests in more detail.

The objectives of the test plan were met and exceeded. The TDC was exposed to significant vibration levels and durations, beyond those anticipated at launch, and continued to operate through all tests without problem. The most severe test was the JPL qualification test at $12.3 \mathrm{Grms}$ for three minutes in both the lateral and axial directions. As a comparison, the RTGs used for Galileo, 
Ulysses, and Cassini missions were tested to $7.7 \mathrm{Grms}$ laterally and 6.1 Grms axially.

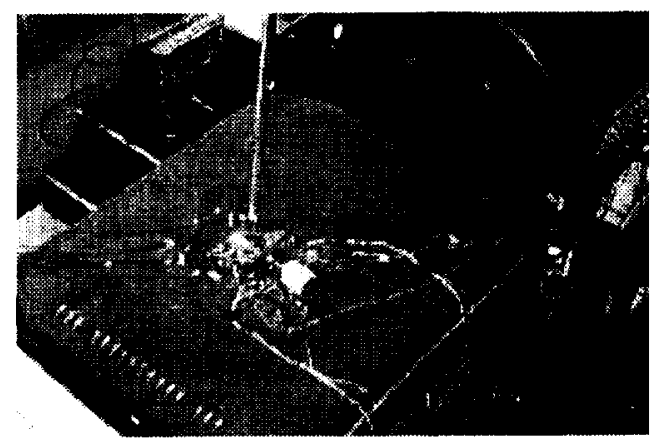

Figure 3. The TDC vibration test at the NASA GRC Structural Dynamics Lab.

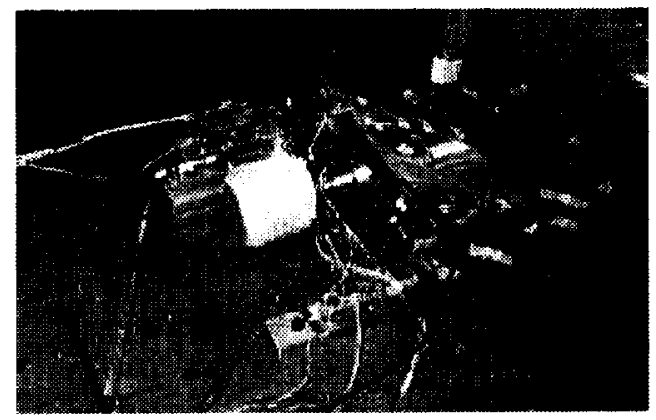

Figure 4. The TDC mounted in the vibration test fixture.

The TDC was operated at full piston stroke and produced power through all of the tests. During the lateral vibration tests, the average power output did vary somewhat, with power output being reduced as the vibration level increased. At the completion of each lateral test, the operation returned to the pre-test condition. Table 1 summarizes the average power output of the TDC during the vibration tests. At the conclusion of the Flight/Qual test in the lateral direction, the TDC produced in excess of the 54-We starting condition due to residual heat that accumulated in the head during the vibration test. After a few minutes, the power output did return to the $54-\mathrm{We}$ starting condition.

The reduced power output can be attributed to several factors. First, during lateral vibration tests, the noncontacting close clearance seals for the power piston, the displacer, and the displacer rod would be operating at time varying clearances. A piston operating coaxially in a bore produces the lowest leakage condition, therefore any deviation from coaxial operation would increase the leakage. Second, as the lateral vibration increased in intensity, the moving parts of the piston/linear alternator and the displacer might contact stationary support surfaces. It was anticipated that this would happen and appropriate materials and coatings were used on the surfaces that would come into contact. Contact would result in some friction that reduces the electric power output. Third, the friction acting on the moving parts could disrupt the tuned dynamics of the free-piston Stirling convertor and thus alter the thermodynamic cycle producing the power. The extent to which these three mechanisms existed, and the possibility of other loss mechanisms has not been studied.

\begin{tabular}{|c|c|c|c|c|}
\hline & \multicolumn{2}{|c|}{ Workmanship } & \multicolumn{2}{c|}{ Flight/Qual } \\
\hline & Lateral & Axial & Lateral & Axial \\
\hline Pre-Test & 54 & 54 & 54 & 54 \\
\hline$-12 \mathrm{~dB}$ & 53 & 54 & 54 & 55 \\
\hline$-6 \mathrm{~dB}$ & 53 & 54 & 50 & 54 \\
\hline$-3 \mathrm{~dB}$ & 51 & 54 & 45 & 55 \\
\hline 0 & 48 & 55 & 38 & 54 \\
\hline Post-Test & 54 & 54 & 57 & 54 \\
\hline
\end{tabular}

Table 1. Average power output (watts) during Workmanship and Flight/Qual random vibration tests.

During the random vibration tests in the axial direction, there was no measurable change in the average power output. At the highest levels of axial vibration, there was a slight, irregular tapping sound coming from the convertor that sounded like metal-to-metal contact. In anticipation of possible over stroke during these tests, teflon bumpers were incorporated in the piston/linear alternator mover of the TDC to prevent damage. The displacer had no such bumper system and therefore was capable of metal-to-metal contact. No instrumentation measured this effect so it is unclear which component produced the sound.

It is worth noting that the TDC passed not just one, but a series of severe tests. The workmanship test was performed twice, once each in the lateral and axial directions. The flight/qualification test was then performed twice, once each in the lateral and axial directions. Before and after each major test, a sine sweep was performed to try to detect structural changes in the hardware; approximately 6 sine sweeps were performed. Thus, the total vibration exposure was far beyond what would be expected at launch. Also, the data from the sine sweeps indicated no structural change as a result of the random vibration tests.

Following successful completion of the vibration tests, the TDC was operated for over 35 hours at full power to accumulate more than $10^{7}$ cycles on the hardware. Per the experience of STC, successful completion of $10^{7}$ cycles is an indication that the flexures have the 
ability for essentially infinite life. This criteria is consistent with the views of the flexure-based Stirling cryocooler industry as an indication of long life. No anomalies were detected during the 35 hours of operation. The TDC was subsequently disassembled and inspected at STC with representatives present from Lockheed Martin Astronautics (LMA), Valley Forge, $P A$, and GRC. It was concluded that no wear or damage was found that could be attributed to the recently completed vibration tests.

\section{Convertor EML/EMC Characterization}

For use as a power system on future NASA science missions, a Stirling radioisotope power system will be required to meet electromagnetic interference and electromagnetic compatibility (EMI/EMC) specifications. Similar to the situation with the vibration loads, there was no EMI/EMC specification applied to the TDC during the initial design.

A team of experts from JPL, GRC and LMA were convened for this assessment. The purpose was to characterize the radiated electromagnetic fields to determine whether the TDC is electromagnetically compatible with the NASA X2000 advanced technology requirements. The tests performed are outlined in table 2 . If the measured levels were found to exceed the specifications, the assessment was also viewed as an initial opportunity to assess the levels that could be achieved in the future and what techniques this might entail. One of the main concerns was that the X2000 radiated emissions requirements used for this evaluation are up to $100 \mathrm{~dB}$ more stringent than the commonly used MIL-STD-461 requirements.

RE0 AC Magnetic Emissions, $50 \mathrm{~Hz}-150 \mathrm{kHz}, 13.3 \mathrm{~cm}$ loop antenna at 4 antenna positions from $12.5 \mathrm{~cm}$ to $1 \mathrm{~m}$

RE04 AC Magnetics, $50 \mathrm{~Hz}-150 \mathrm{kHz}$, larger loop antenna at 3 positions from $25 \mathrm{~cm}$ to $1 \mathrm{~m}$

Search coil measurements, $25 \mathrm{~cm}$ and $1 \mathrm{~m}$ ( 3 axis)

RE02 Electric Field Emissions, $50 \mathrm{~Hz}-150 \mathrm{kHz}$, and $14 \mathrm{kHz}-1 \mathrm{GHz}$ at $1 \mathrm{~m}$

CE01 test, measured at TDC interface for information only, not a spec

Characterized controller voltage and current waveforms

Magnetic Field Emissions test using partial mumetal shields over the alternators

Table 2. EMI/EMC tests performed on the TDC.
The EMI/EMC laboratory at GRC was selected as the site for the assessment. Two operational TDCs and the needed support equipment were installed in the EMIEMC lab. Initial tests were run with the TDCs configured in the alternator-to-alternator configuration as shown in figure 1. Later in the test sequence, the configuration was changed so that the TDCs were tested in a hot-end to hot-end configuration as shown in figure 5. It should be noted that the TDCs were never optimized to reduce EMC, and further that there was no attempt to minimize loop area or clock the TDCs relative to one another for this particular test, nor to provide any shielding in the TDC.

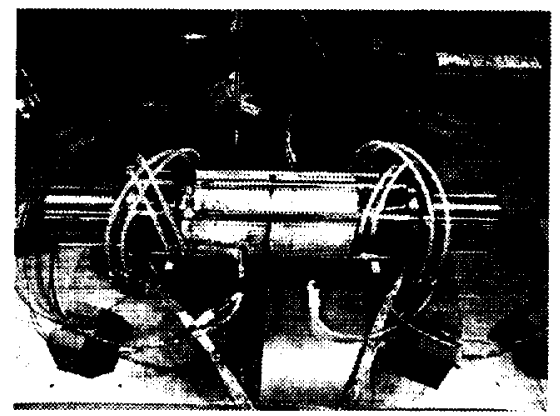

Figure 5. A pair of TDCs on test at the GRC EMI/EMC Laboratory.

Based on the test data, the TDCs would meet the requirements for missions such as Europa Orbiter and Pluto Kuiper Express, but would exceed the Solar Probe magnetic field requirements (driven by the science package) by up to about $100 \mathrm{~dB}$ at the $80 \mathrm{~Hz}$ operating frequency. The electric field emissions exceeded the Solar Probe electric field requirements by about $60 \mathrm{~dB}$, but further testing showed that these emissions were primarily being radiated by the interconnecting cable and were reduced by $30 \mathrm{~dB}$ with minimal effort. Harmonic content was largely a function of the current waveform which is expected to be near sinusoidal with few harmonics in the flight unit.

It was the conclusion that significant improvement in magnetic field emissions are available by optimizing wiring layout and providing counter-loops when necessary. It was also concluded that it is possible to use the TDC for science missions with plasma experiments; however, care would need to be taken to minimize current loops and magnetic shielding would also be required.

\section{Heater Head Life Assessment}

Heater head life is a critical element for achieving the $100,000+$ hour life of the convertor. NASA GRC 
materials and structures personnel have developed an approach to characterize the long-term durability of the heater head using relatively short-term extrapolation methods ${ }^{11}$. A similar assessment was previously completed for a 12.5-kWe Stirling convertor as part of the NASA CSTI efforts for SP-100 ${ }^{12}$. Life prediction models will be selected, and an independent thermal and structural FEA completed. The IN718 heater head material in the final process condition that will be used in the convertor will be characterized for creep $(<20,000$ hours), low cycle fatigue, thermal. and tensile data. Structural benchmark testing will also be done consisting of accelerated life tests on prototypical heater heads. Results of this testing and the IN718 material tests will be used to calibrate and validate the life prediction model. This calibrated model will then be used to project the heater head lifetime. Successful completion of these efforts is expected to give high confidence in the ability of the heater head to meet the operational life requirements.

To date, life prediction models have been identified, and the heater head FEA model completed. Creep testing has been initiated for the IN718 heater head material. A high temperature, high pressure test system has been designed and is now being assembled for the heater head accelerated life tests. This will apply both temperature gradients and pressure conditions based on those in the actual convertor. Elevated pressure and/or temperature conditions will be used to accelerate the testing.

A study was completed to investigate the possible depletion of chromium from the IN718 by the longterm, high-temperature exposure to the vacuum of space. Chromium depletion would decrease material creep resistance and strength. A model was set up and then characterized and verified by accelerated aging tests on IN718. This model was then used to predict the chromium loss after 100,000 hours at the $650^{\circ} \mathrm{C}$ hot-end temperature. The final results showed negligible chromium loss at these conditions.

An evaluation of the joining methods used in the convertor is also being conducted. Critical joints will be thermally aged and microstructurally investigated. This will include, in particular, the critical close-out hermetic seal. A test setup to evaluate the hermetic seal has been designed. The organic materials in the convertor are being reviewed for any compatibility and outgassing concerns; these efforts are also supporting the selection of radiation-hard organics (see section on Ionizing Radiation Survivability Assessment).

\section{Linear Alternator Finite Element Analyses}

Lightweight linear alternators with high efficiency are a key to obtaining the potential of the Stirling convertor for the radioisotope power system. NASA GRC has been developing finite element analyses (FEA) tools for performing various linear alternator analyses, including thermal and electromagnetic analyses and evaluating design configurations. A three-dimensional magnetostatic model of the TDC linear alternator has been developed using Ansoft's Maxwell 3D finite element method software ${ }^{13}$.

A key thermal analysis was first completed. The coldend of the convertor is expected to operate in the range of $80-120^{\circ} \mathrm{C}$. The higher temperatures of this range could be marginal for the use of $\mathrm{NdFeB}$ magnets. However, it was recognized by LMA, one of the DOE contractors analyzing system designs, that the convertor pressure vessel will also act as a radiator. A model was developed by NASA GRC that included the linear alternator, pressure vessel, piston, and radiator. Boundary conditions and inputs included a $120^{\circ} \mathrm{C}$ convertor cold-end temperature, radiation sink temperature of $-40^{\circ} \mathrm{C}$, full power output of $55 \mathrm{We}$ from the convertor with an $85 \%$ efficient linear alternator, a surface conductance between adjacent parts of $0.31 \mathrm{~W} /{ }^{\circ} \mathrm{C}-\mathrm{cm}^{2}$, and an emissivity of 0.91 with an absorptivity/emissivity ratio of 1.0 for the radiation heat transfer. An average magnet temperature of $73^{\circ} \mathrm{C}$ was obtained from the analysis. This is expected to be conservative as the model did not include any convection heat transfer from the helium inside the convertor pressure vessel. This calculated magnet temperature is readily in the typical operating range of $\mathrm{NdFeB}$ magnets, and this calculation resolved concerns over the magnet selection. The calculated linear alternator temperature levels are also key inputs to the selection of radiation-hard organic materials for use in the alternator (see section on Ionizing Radiation Survivability Assessment).

Electromagnetic calculations of the TDC linear alternator open circuit voltage have also been recently completed and compared to the value measured by STC at room temperature ${ }^{13}$. The NASA GRC model calculated $98.0 \mathrm{Vrms}$ at $23^{\circ} \mathrm{C}$ while STC measured 97.0 Vrms. Dynamic circuit simulation software capable of working with Maxwell 3D is expected soon: this will allow complete simulations under load.

This FEA tool should be useful for evaluating both linear alternator performance and design variations. A future task is planned to evaluate a lightweight linear alternator concept that has been previously tested by STC and had performance shortfalls. The FEA will be 
used to evaluate the alternator flux profiles and identify potential design modifications with STC to improve performance.

\section{Permanent Magnet Aging Tests}

$\mathrm{NdFeB}$ permanent magnets are used in the TDC linear alternators. Magnet choice is dependent on the final convertor cold-end temperature chosen based on system analyses (now expected to be between 80 and $120^{\circ} \mathrm{C}$ ), magnet temperature calculations (preliminary calculations indicate that the magnet operating temperature is about $70-80^{\circ} \mathrm{C}$ - see previous section), and the safety margin necessary to prevent demagnetization. Characterization testing of appropriate $\mathrm{NdFeB}$ magnets will first be done using an existing test rig shown in figure 6 that was developed for testing SmCo magnets during the previous NASA CSTI research for SP-100 ${ }^{14}$. Selected NdFeB magnets will then be put on short-term and long-term aging tests at operating temperature and in a demagnetizing field to quantify any potential magnet degradation with time and temperature. Such degradation could affect both the remanent magnetization and the demagnetization resistance.

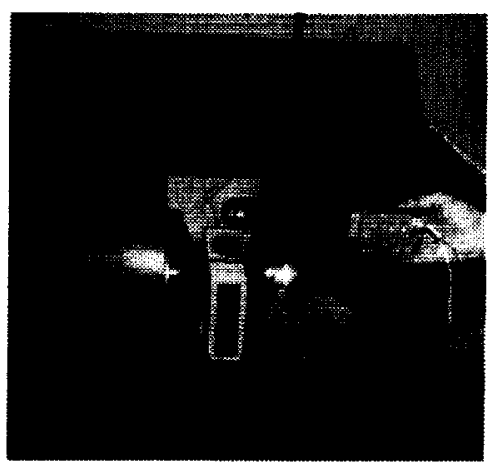

Figure 6. Magnet characterization test rig.

The characterization testing of $9 \mathrm{NdFeB}$ magnet types from 3 different manufacturers has been mostly completed. B-H curves for two different samples of each magnet type were measured over a range of temperatures from room temperature to $150^{\circ} \mathrm{C}$. Comparisons between one of the better (for this application) $\mathrm{NdFeB}$ magnet types and one of the better $\mathrm{Sm}_{2} \mathrm{Co}_{17}$ magnet types tested previously are shown in figures 7 and 8 . Figure 7 compares the magnet remanence, a measure of magnet strength, over a range of temperatures. It can be seen that the crossover point in magnet strength between the NdFeB and $\mathrm{SmCo}$ is around $190^{\circ} \mathrm{C}$. Figure 8 compares the intrinsic coercivity, a measure of demagnetization resistance, over a range of temperatures. At the expected magnet operating temperatures for the Stirling convertor, it can be seen from the two figures that the NdFeB magnets provide higher strength but lower demagnetization resistance.

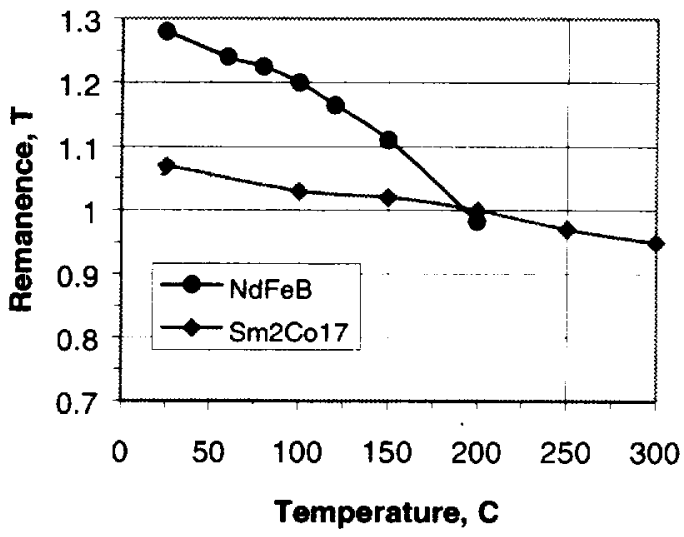

Figure 7. Comparison of magnet remanence vs. temperature for $\mathrm{NdFeB}$ and $\mathrm{SmCo}$ magnets.

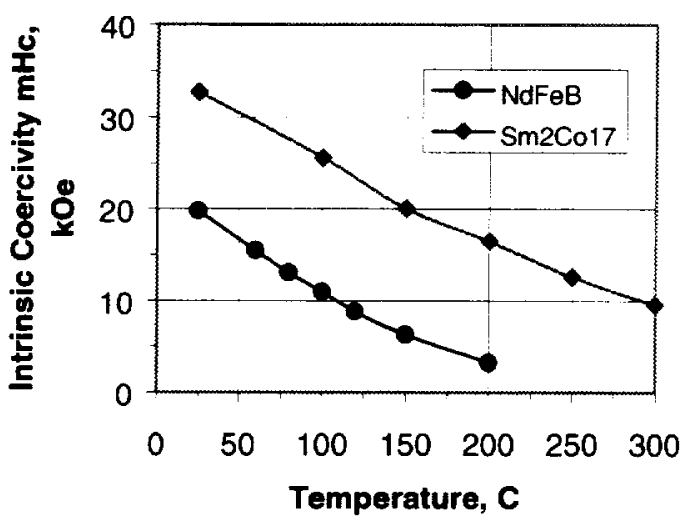

Figure 8. Comparison of magnet intrinsic coercivity vs. temperature for $\mathrm{NdFeB}$ and $\mathrm{SmCo}$ magnets.

Based on the NdFeB characterization tests, several $\mathrm{NdFeB}$ magnet types will be selected for short-term magnet aging tests. A magnet aging rig has been designed and fabricated by KJS Associates Inc. Indianapolis, IN and will soon be installed at NASA GRC. This test rig will allow up to 10 magnet samples to be tested at once in an inert gas. The inert gas will prevent oxidation effects from occurring over the test period and influencing the results. In actual operation, the magnets are located in the helium environment of the convertor. The samples will be maintained at a selected temperature and with a fixed DC demagnetizing field applied. This demagnetizing field will be chosen based on the maximum demagnetizing field that the magnets see in operation. 
Preliminary short-term aging tests have been completed using the magnet characterization rig. Three NdFeB magnet types have been tested for about 100 hours at $120^{\circ} \mathrm{C}$ and in a 6-kOe demagnetizing field. No measurable change in magnet characteristics were found after these tests. Further short-term aging tests with the aging test rig may be run at higher temperatures. Either one or two NdFeB magnet types will then be chosen for the long-term aging tests. It is planned to run the long-term tests for a minimum of 12,000 hours. Magnet samples will be periodically removed from the test rig to quantify the rate of aging. These results will then be used to project magnet characteristics over the 6-15 year mission lifetimes.

\section{In-House Testing of 350 -We Convertors and 55-We TDCs}

An in-house Stirling test facility is currently being established for testing both $350-\mathrm{We}$ and $55-\mathrm{We}$ convertors. Four 55-We TDCs are now being built by STC for NASA GRC. These will essentially be the same as the TDCs tested previously by STC. One main difference is that they will incorporate radiation-hard organic materials for the piston bearings and bumpers and in the linear alternator (see next section). The TDCs will be arranged in opposed pairs in a hot-end to hot-end configuration; this configuration was used during previous EMI/EMC testing at NASA GRC and is shown in figure 5 .

The TDC convertors are expected to be used first for independent performance verification and further launch environment testing. They will also serve as a functional test bed for demonstrating the radiation-hard organics.

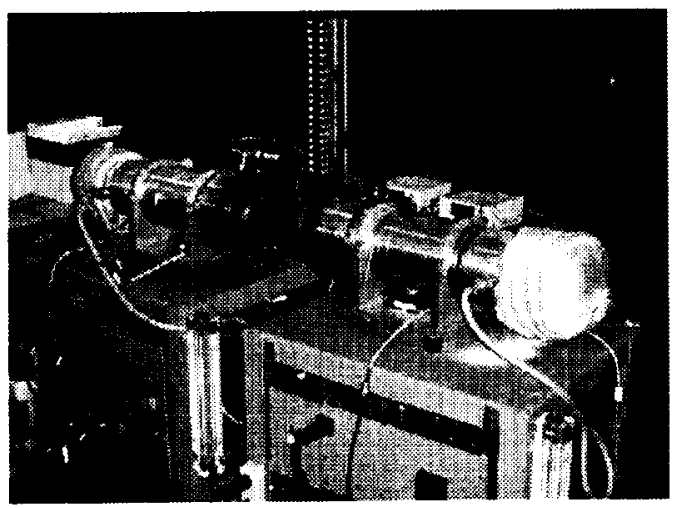

Figure 9. Two opposed 350-We convertors on test at STC.

Two 350-We convertors will be delivered to NASA GRC that were built under the NASA Phase II SBIR that developed the synchronous connection for two thermodynamically independent convertors ${ }^{3.4}$. These convertors are shown on test at STC in figure 9. STC has also used these convertors for developing the Adaptive Vibration Reduction System under a further NASA Phase II SBIR ${ }^{3.4}$. These $350-W e$ convertors as well as the second pair of TDCs will be used by NASA GRC for controls technology development, including some further developments of the SBIR technologies.

\section{Ionizing Radiation Survivability Assessment}

Future missions for a Stirling radioisotope power system include a possible mission to the Jupiter moon Europa. The Europa radiation environment is harsh, and this ionizing radiation around Jupiter is much more severe than that produced by the GPHS radioisotope heat source.

As part of a DOE/NASA assessment of the Stirling technology, NASA GRC evaluated the radiation effects on the organic materials in the Stirling convertor ${ }^{15}$. Experts were also consulted from JPL, LMA, and General Electric, Schenectady, NY. The total expected ionizing dose inside the convertor was estimated at 4 MRAD considering the intrinsic shielding provided by the pressure vessel. Each organic material used in the Stirling convertor was identified. These included piston bearing coatings, piston bumpers, and alternator adhesives and electrical insulations. Each separate material was evaluated for acceptability, and new organic materials were recommended where necessary. Both STC and vendors of the organic materials were consulted as to the satisfactory functional use of the recommended materials. STC completed functional tests as required for some of the materials under consideration.

In each case, a satisfactory radiation-hard organic has been identified. These materials are now being incorporated into the TDC convertors that STC is currently building for NASA GRC. The testing of these convertors will verify the functionality for each of the modified organics.

\section{Failure Modes and Effects Analysis}

An independent reliability assessment of the TDC was performed at GRC. The assessment included two tasks. The first task was to develop a Failure Modes and Effects Analysis (FMEA). This analysis was intended to address the Stirling convertor, but not the radiator, controller, structural interface, and GPHS modules and housing, which were all viewed to be part of the system and beyond the envelope of the TDC. The second task was to develop a life and reliability model using all available test data that were deemed relevant. The 
ultimate purpose of this second task was to determine if a flight version of the TDC was capable of completing a 14-year mission.

An FMEA was performed for the TDC looking at the component level. This analysis included all phases of the TDC operational life starting when the fueled GPHS modules are loaded into the system through the completion of the mission. Following this, a top level FMEA was generated to determine if there were any failures in external systems that would cause a critical failure in the TDC.

Based on the results from the component level FMEA, a Critical Items List (CIL) was generated. A critical item was defined as an item whose failure would prevent the TDC from producing power at or near the full capacity. A failure that shuts down the TDC but allows a restart was not considered a critical failure. A total of 14 components were identified on the CIL, as shown in table 3 .

\begin{tabular}{|r|l|}
\hline 1 & Hermetic closure, pressure vessel \\
\hline 2 & Hermetic closure, piston housing \\
\hline 3 & Hermetic closure, electric feed throughs \\
\hline 4 & Aft bearing support spider \\
\hline 5 & Heater head assembly \\
\hline 6 & Over stroke protection bumper \\
\hline 7 & Over stroke protection bumper stops \\
\hline 8 & Linear alternator stator permanent magnets \\
\hline 9 & Linear alternator stator insulation \\
\hline 10 & Linear alternator mover assembly \\
\hline 11 & Displacer flexures \\
\hline 12 & Piston flexures \\
\hline 13 & Flexure stack fasteners \\
\hline 14 & Linear alternator stator laminations \\
\hline
\end{tabular}

Table 3. TDC Critical Items List.

To evaluate the potential for long life, a life and reliability analysis was performed on each of the items identified on the CIL. A number of sources of information were used, including test data, materials data, and component design data. The conclusion was that there was sufficient relevant data and that all of the design issues were well understood and could be managed within the current quality practices of the aerospace industry.

\section{Parametric Study of Radiator Concepts}

Orbital Sciences Corporation ${ }^{16,17}$, Germantown, MD, and $\mathrm{LMA}^{18}$ have provided system analyses for DOE. As part of the Interagency Agreement with DOE, NASA GRC has contributed a parametric study of heat pipe and non-heat pipe radiator concepts using both state-of-the-art and advanced high thermal conductivity materials $^{19}$. The heat pipe concepts were based on an earlier Orbital Sciences system concept shown in figure 10; see references ${ }^{16,17}$ for later Orbital Sciences system designs. The non-heat pipe concept that was evaluated was developed by NASA GRC and is shown in figure 11. This concept uses solid disks and eliminates any concerns with heat pipe reliability, such as sensitivity to micrometeoroid damage.

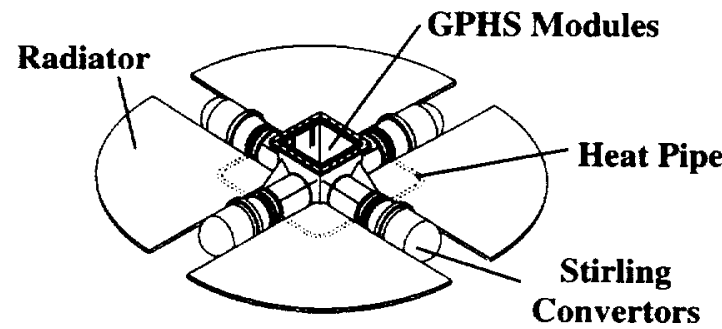

Figure 10. Orbital Sciences Corporation system concept $^{20}$.

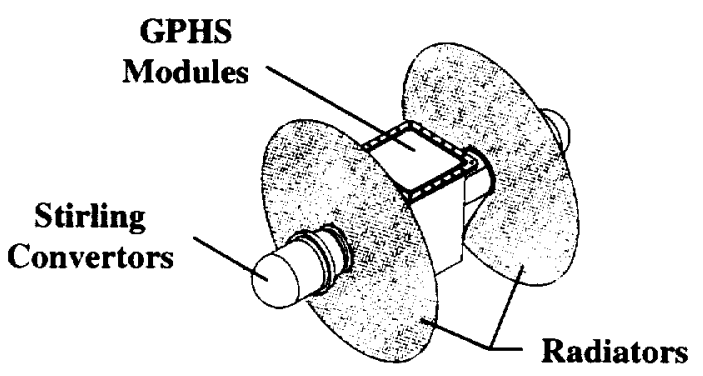

Figure 11. Non-heat pipe radiator concept.

For the heat pipe concepts, layouts using heat pipes located optimally for performance and radiator size were compared with layouts with the heat pipe fixed at the radial location of the convertor cooler (which was assumed to be easier to fabricate). The non-heat pipe radiators use thermal conduction through solid disks mounted perpendicular to the convertor axis of motion. Flat, tapered, and parabolic surfaces were considered for the solid disks. Both two- and four-convertor system designs were evaluated for both heat pipe and non-heat pipe concepts.

Materials considered for the radiator fins included aluminum, beryllium, carbon composite, and thermal pyrolitic graphite (TPG). TPG is an advanced highthermal conductivity material and is not an available radiator technology at this time. The TPG must be encapsulated within another material to provide strength. TPG encapsulants considered in the study 
were aluminum, beryllium, and carbon composite. A Z-93 radiator surface coating with high emissivity and low absorptivity was assumed for the study.

These conceptual radiator evaluations were done with a dedicated radiator analysis tool, GPHRAD, recently developed at NASA GRC ${ }^{21}$. GPHRAD is a finite difference computational code developed for the analysis and design of circular sector radiators. It includes a novel subroutine to determine equilibrium space sink temperatures anywhere within the Solar System $^{22}$. This takes into account the radiator surface characteristics, view factor to space, distance from the sun and any planets, and on-board heat generation.

For a nominal 105-We power system with two opposed Stirling convertors and a convertor cold-end temperature of $120^{\circ} \mathrm{C}$, total radiator mass was found to be as low as $1.75 \mathrm{~kg}$ for a non-heat pipe concept and as low as $2.17 \mathrm{~kg}$ for a heat pipe concept. As the layouts went from the more complex (heat pipe radiators with heat pipes requiring a number of bends) to the simpler (simple disks and no heat pipes), the benefits of using the advanced high thermal conductivity TPG increased. However, designs with aluminum, beryllium, and carbon composites were also found to be attractive in terms of mass and thermal performance for each potential layout. The best non-heat pipe designs have outer radii that are $2 / 3$ as large as the best designs using heat pipes; however, these best non-heat pipe designs require the use of TPG fins. In general, maximum temperature differences across the radiator were minimized by using optimally-located heat pipes and TPG material.

A view factor of 1.5 was assumed for these calculations. A sensitivity analysis to view factor showed that view factor significantly affects radiator size and mass and needs to be carefully calculated for a given system and spacecraft layout.

\section{Concluding Remarks}

The Department of Energy, NASA Glenn Research Center, and Stirling Technology Company are developing a Stirling convertor for a high-efficiency radioisotope power system to provide spacecraft onboard electric power for NASA deep space missions. Rapid progress has been made, and a Stirling power system has now been identified for potential use on the Europa Orbiter and Solar Probe missions.

A technology assessment was recently completed by DOE and NASA with a joint government/industry team to evaluate the technology readiness of STC's 55-We Technology Demonstration Convertor. The team concluded that no technical barriers exist and that the Stirling convertor is ready for the next step towards developing the Stirling technology into a radioisotope power system for future NASA deep space missions. A DOE procurement solicitation for a system integrator for this Stirling radioisotope power system has since been released.

NASA GRC is playing a key role in the overall development of the Stirling convertor for this application. As part of the NASA GRC in-house supporting technology project, four key tasks of the technology assessment were completed. These were the demonstration of the Stirling convertor operation under launch environments, convertor EMI/EMC characterization, survivability assessment of the convertor organic materials in a high-radiation environment, and failure modes and effects analysis. Further in-house tasks are providing life assessments for the heater head and permanent magnets, an independent performance verification for the convertor, a joining evaluation, and FEA analyses of the linear alternator. These NASA GRC efforts are moving along rapidly with a number of significant accomplishments in the first year of the project. In addition, Stirling technology expertise is provided to DOE as part of a Space Act Agreement. Under this Space Act Agreement, a parametric study of radiator concepts was also completed.

\section{References}

[1] White, M.A.; Qiu, S.; Olan, R.W.; and Erbeznik, R.M.: Technology Demonstration of a Free-Piston Stirling Advanced Radioisotope Space Power System, Proceedings of the Space Technology and Applications International Forum, 1999.

[2] White, M.A.; Qiu, S.; and Augenblick, J.E.: Preliminary Test Results from a Free-Piston Stirling Engine Technology Demonstration Program to Support Advanced Radioisotope Space Power Applications, Proceedings of the Space Technology and Applications International Forum, 2000.

[3] Thieme, L.G.; Qiu, S.; and White, M.A.: Technology Development for a Stirling Radioisotope Power System for Deep Space Missions, Proceedings of the $34^{\text {th }}$ Intersociety Energy Conversion Engineering Conference 1999, NASA/TM-2000-209767, 2000.

[4] Thieme, L.G.; Qiu, S.; and White, M.A.: Technology Development for a Stirling Radioisotope Power System, Proceedings of the Space Technology and Applications International Forum - 2000, NASA/TM-2000-209791, 2000. 
[5] Bents, D.J. ; Geng, S.M.; Schreiber, J.G.; Withrow, C.A.; Schmitz, P.C.; and McComas, T.J.: Design of Multihundredwatt DIPS for Robotic Space Missions, Proceedings of the $26^{\text {th }}$ Intersociety Energy Conversion Engineering Conference, NASA TM-104401, 1991.

[6] Mason, L.S.: Technology Projections for Solar Dynamic Power, NASA/TM-1999-208851, 1999.

[7] Mason, L.S.: Solar Stirling for Deep Space Applications, Proceedings of the Space Technology and Applications International Forum - 2000, NASA/TM-1999-209656, 1999.

[8] Schreiber, J.G.: A Deep Space Power System Option Based on Synergistic Power Conversion Technologies, Proceedings of the Space Technology and Applications International Forum, 2000.

[9] Hughes, W.O.; McNelis, M.E.; and Goodnight, T.W.: Vibration Testing of an Operating Stirling Convertor, Proceedings of the Seventh International Congress on Sound and Vibration, Garmisch-Partenkirchen, Germany, 4-7 July 2000.

[10]Goodnight, T.W.; Hughes, W.O.; and McNelis, M.E.: Dynamic Capability of an Operating Stirling Convertor, to be published in the Proceedings of the $35^{\text {th }}$ Intersociety Energy Conversion Engineering Conference, 2000.

[11] Bartolotta, P.; Bowman, R.; Krause, D.; and Halford, G.: Long-Term Durability Analysis of a 100,000-Hour Stirling Power Convertor Heater Head, to be published in the Proceedings of the $35^{\text {th }}$ Intersociety Energy Conversion Engineering Conference, 2000.

[12] Abdul-Aziz, A., Bartolotta, P., Tong, M., and Allen, G.: An Experimental and Analytical Investigation of Stirling Space Power Convertor Heater Head, NASA TM-107013, 1995.

[13] Geng, S.M.; Schwarze, G.E.; and Niedra, J.M: A 3-D Magnetic Analysis of a Linear Alternator for a Stirling Power System, to be published in the Proceedings of the $35^{\text {th }}$ Intersociety Energy Conversion Engineering Conference, 2000.

[14] Niedra, J.M.: Comparative M-H Characteristics of 1-5 and 2-17 Type Samarium-Cobalt Permanent Magnets to 300 C, NASA CR-194440, 1994
[15] Golliher, E.L. and Pepper, S.V.: Organic Materials Ionizing Radiation Susceptibility for the Outer Planets/Solar Probe Radioisotope Power Source, to be published in the Proceedings of the $35^{\text {th }}$ Intersociety Energy Conversion Engineering Conference, 2000.

[16] Or, C.; Kumar, V.; Carpenter, R.; and Schock, A.: Self-Supporting Radioisotope Generators with STC-55W Stirling Convertors, Proceedings of the Space Technology and Applications International Forum, 2000.

[17]Or, C.; Carpenter, R.; Schock, A.; and Kumar, V.: Performance of the Preferred Self-Supporting Radioisotope Power System with STC 55-W Stirling Convertors, Proceedings of the Space Technology and Applications International Forum, 2000.

[18] Cockfield, R.D.: Radioisotope Stirling Generator Concepts for Planetary Missions, to be published in the Proceedings of the $35^{\text {th }}$ Intersociety Energy Conversion Engineering Conference, 2000.

[19]Juhasz, A.J.; Tew, R.C.; and Thieme, L.G.: Parametric Study of Radiator Concepts for a Stirling Radioisotope Power System Applicable to Deep Space Missions, NASA/TP_2000-209676, to be published in 2000 .

[20] Schock, A.; Or, C.; and Kumar, V.: Radioisotope Power System Based on Improved Derivative of Existing Stirling Engine and Alternator, Proceedings of the Space Technology and Applications International Forum, 1999.

[21] Juhasz, A.J. and Thieme, L.G.: Design and Analysis Code for Radiators of Stirling Power Systems With General Purpose (GPHS) Heat Sources, Proceedings of the $34^{\text {th }}$ Intersociety Energy Conversion Engineering Conference, 1999.

[22] Juhasz, A.J.: An Analysis and Procedure for Determining Space Environmental Sink Temperatures with Selected Computational Results, to be published in the Proceedings of the $35^{\text {th }}$ Intersociety Energy Conversion Engineering Conference, Paper No. 2000-3010, 2000. 



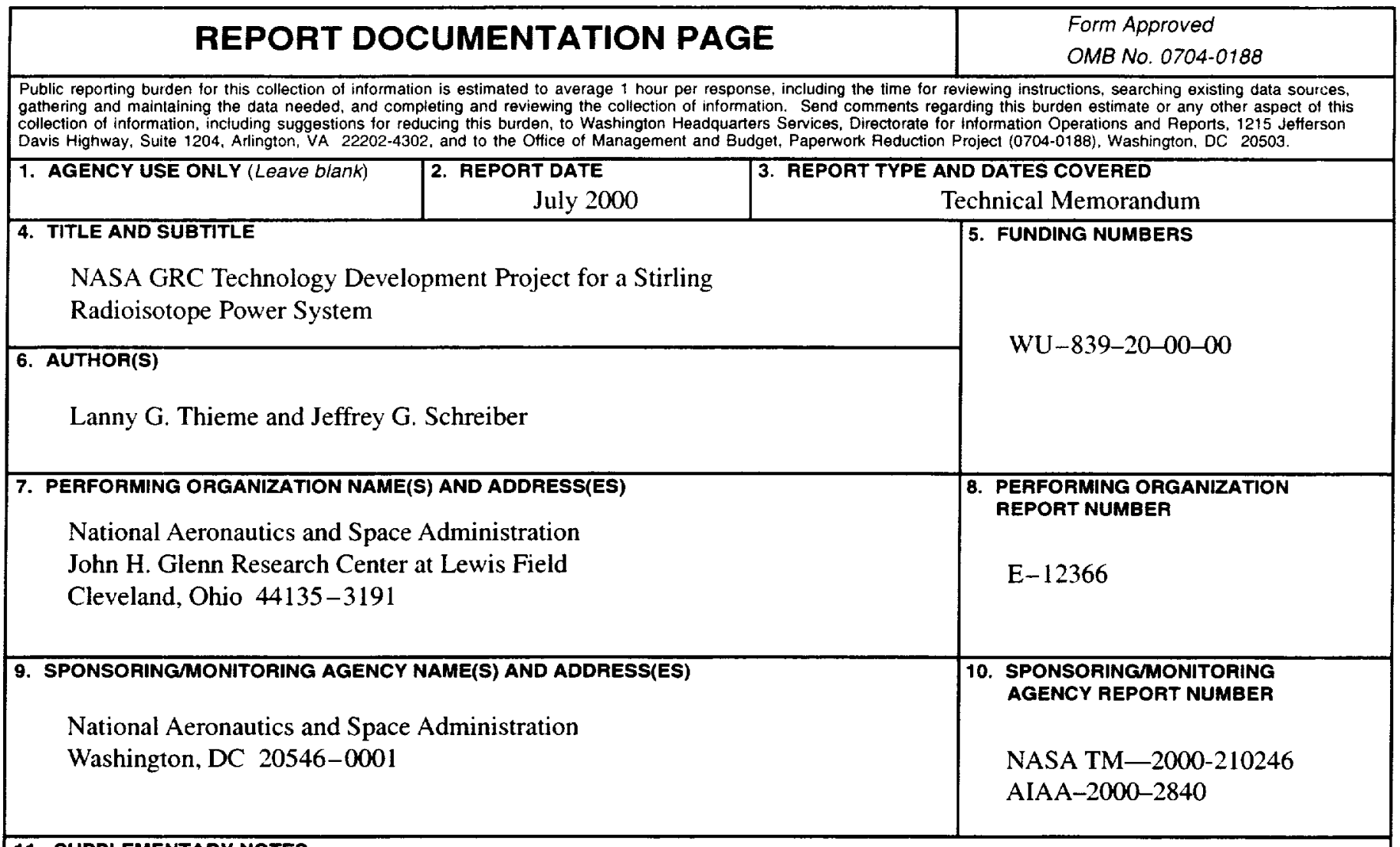

11. SUPPLEMENTARY NOTES

Prepared for the 35th Intersociety Energy Conversion Engineering Conference sponsored by the American Institute of Aeronautics and Astronautics, Las Vegas, Nevada, July 24-28, 2000. Responsible person, Lanny G. Thieme, organization code $5490,(216) 433-6119$.

\begin{tabular}{|l|l}
\hline 12a. DISTRIBUTION/AVAILABILITY STATEMENT & 12b. DISTRIBUTION CODE
\end{tabular}

Unclassified - Unlimited

Subject Categories: 20 and $44 \quad$ Distribution: Nonstandard

This publication is available from the NASA Center for AeroSpace Information. (301) 621-0390.

13. ABSTRACT (Maximum 200 words)

NASA Glenn Research Center (GRC), the Department of Energy (DOE), and Stirling Technology Company (STC) are developing a Stirling convertor for an advanced radioisotope power system to provide spacecraft on-board electric power for NASA deep space missions. NASA GRC is conducting an in-house project to provide convertor, component, and materials testing and evaluation in support of the overall power system development. A first characterization of the DOE/ STC 55-We Stirling Technology Demonstration Convertor (TDC) under the expected launch random vibration environment was recently completed in the NASA GRC Structural Dynamics Laboratory. Two TDCs also completed an initial EMI characterization at NASA GRC while being tested in a synchronized, opposed configuration. Materials testing is underway to support a life assessment of the heater head, and magnet characterization and aging tests have been initiated. Test facilities are now being established for an independent convertor performance verification and technology development. A preliminary FMEA, initial FEA for the linear alternator, ionizing radiation survivability assessment, and radiator parametric study have also been completed. This paper will discuss the status, plans, and results to date for these efforts.

14. SUBJECT TERMS

Stirling engines; Nuclear electric power generation; Deep space; Random vibration; Vibration tests;

Electromagnetic compatibility; Electromagnetic interference; Life; Durability; Linear alternator;

Finite element method; Permanent magnets; Ionizing radiation; Radiators

\begin{tabular}{|c|c|c|}
\hline $\begin{array}{c}\text { 17. SECURITY CLASSIFICATION } \\
\text { OF REPORT } \\
\text { Unclassified }\end{array}$ & $\begin{array}{c}\text { 18. SECURITY CLASSIFICATION } \\
\text { OF THIS PAGE } \\
\text { Unclassified }\end{array}$ & $\begin{array}{c}\text { 19. SECURITY CLASSIFICATION } \\
\text { OF ABSTRACT } \\
\text { Unclassified }\end{array}$ \\
\hline
\end{tabular}

NSN 7540-01-280-5500

Standard Form 298 (Rev. 2-89) Prescribed by ANSI Std. Z39-18 298-102 
